\title{
Tags below three percent of body mass increase nest abandonment by rhinoceros auklets, but handling impacts decline as breeding progresses
}

\author{
Alice Sun ${ }^{1}$, Shannon Whelan ${ }^{1, *}$, Scott A. Hatch ${ }^{2}$, Kyle H. Elliott ${ }^{1}$ \\ ${ }^{1}$ Department of Natural Resource Sciences, McGill University, Ste Anne-de-Bellevue, Quebec H9X 3V9, Canada \\ ${ }^{2}$ Institute for Seabird Research and Conservation, Anchorage, Alaska 99516, USA
}

\begin{abstract}
Biologging has revealed many of the mysteries surrounding seabird behavior far from land. However, tagging seabirds with biologgers may influence the very traits they are designed to observe. Such 'tag effects' are often argued to be minimal below a threshold of $3 \%$ of body mass. Nonetheless, few studies carefully separate handling from tagging effects, so the effect of tag size is often confounded with the effect of handling. Puffins, including rhinoceros auklets Cerorhinca monocerata, are notoriously difficult to work with due to high nest abandonment rates. To examine tagging and handling effects in rhinoceros auklets, we compared abandonment rates of individuals equipped with a GPS weighing $2.3 \%$ of body mass with abandonment rates of birds handled but not equipped, and of birds not handled at all (controls). We used the egg flotation technique to estimate egg development and predict hatching date, thus allowing treatments to be applied at the appropriate time. Handling more than doubled abandonment rates compared to control birds, and tagging more than doubled abandonment rates compared to birds that were handled but not tagged. Abandonment rates decreased as incubation progressed and were lowest during chick-rearing. We conclude that both handling and tagging of auklets increase abandonment, and that effects are lowest during chick-rearing.
\end{abstract}

KEY WORDS: Biologging devices - Experiment - Tracking - Desertion - Egg flotation · Reproduction $\cdot$ Rhinoceros puffin

\section{INTRODUCTION}

Biologging provides an opportunity to observe behavior that is 'unobservable' for remotely foraging species such as seabirds. A better understanding of marine ecosystem health through the use of predators foraging at higher trophic levels (e.g. seabirds) is one example of the benefits of biologging, and seabirds mostly nest in dense colonies on islands, making them easy to observe, capture and manipulate (Sydeman et al. 2001, Piatt et al. 2007, Wakefield et al. 2009, Hatch 2013). With tracking devices becom-

\footnotetext{
*Corresponding author: shannon.whelan2@mail.mcgill.ca
}

ing smaller and more advanced, data on seabird movement can be more easily obtained and can accelerate our understanding of marine ecosystems (e.g. Wilson et al. 2002, Wakefield et al. 2009). By combining knowledge of ocean conditions, breeding biology, and foraging behavior, we can discern overall ecosystem health (Lescroël et al. 2016, BrissonCuradeau et al. 2017), monitor the human ecological footprint (Bodey et al. 2014), and make management decisions (Gaston et al. 2013).

Although seabirds are good indicators of marine ecosystems and can be exploited for biologging, the

() The authors 2020. Open Access under Creative Commons by Attribution Licence. Use, distribution and reproduction are unrestricted. Authors and original publication must be credited. 
effects of attaching a device on a bird can negatively impact survival and reproductive output (Fraser et al. 1999, Vandenabeele et al. 2012, Bodey et al. 2018, Portugal \& White 2018). In extreme cases, seabirds may die if carrying the device is too energetically costly or the attachment procedure causes too much stress (e.g. Uria aalge, U. lomvia, and Fratercula cirrhata, Hatch et al. 2000; Stercorarius skua, Thaxter et al. 2016). More commonly, deploying a transmitter will cause adults to abandon their breeding attempt or to return to the colony less frequently (Pygoscelis antarctica, Croll et al. 1996; Puffinus griseus, Söhle et al. 2000); reduced nest attendance can slow chick growth rates (Ptychoramphus aleuticus, Ackerman et al. 2004; Calonectris borealis, Villard et al. 2011). Even biologging devices that follow the $3 \%$ guideline (where the logger needs to be $<3 \%$ of the bird's body weight; Wilson et al. 2002, Burger \& Shaffer 2008) can still cause nest abandonment, lower feeding rates, and decreased reproductive success (Croll et al. 1996, Söhle et al. 2000). Although such 'tag effects' are widely reported, few studies carefully separate device effects from handling effects, so parameters influencing responses to handling and tagging often remain unknown (Elliott 2016).

Indeed, even handling alone has well-documented effects of research disturbance. Intensive handling can reduce foraging efficiency, decrease fledging success, and depress the mass of adult birds (e.g. rhinoceros auklets Cerorhinca monocerata, Kato et al. 2003). Parents often desert their eggs when frequent researcher visits are made, especially early in incubation (Götmark 1992, Rodway et al. 1996, Carey 2009). For example, around $88 \%$ of studies on alcids and larids have shown that research activities have a visible impact (Götmark 1992). A study by Blackmer et al. (2004) found nearly $91 \%$ of breeding failures in Leach's storm petrels Oceanodroma leucorhoa were attributable to nest desertion due to handling-related disturbance. Investigators can also cause reduced chick growth; undisturbed chicks have been found to be heavier and to have longer wings (Aethia pusilla and A. cristatella, Piatt et al. 1990). In some cases, chick survival may also be impacted. Research handling can decrease nest attendance, leaving the chick vulnerable to predation and harsh weather (Rissa tridactyla, Sandvik \& Barrett 2001). In some studies, however, hatching success and chick growth were unaffected by different intensities of disturbance (A. cristatella, Fraser et al. 1999). Nonetheless, studying investigator disturbance can prove useful, as it can help develop techniques to minimize impact and reduce bias in results.
Rhinoceros auklets are generalist predators that dive up to $30 \mathrm{~m}$ to capture fish (Burger et al. 1993) and adjust their diet in response to prey availability (Davoren 2000, Carle et al. 2015). Prey availability can also be reflected in their reproductive success, where lack of prey reduces breeding success and can influence phenology (Watanuki et al. 2009), and therefore these birds are considered an indicator of fish stocks (Cunningham et al. 2018). To date, only a few studies have applied biologging techniques to study rhinoceros auklet behavior (Kato et al. 2003, Cunningham et al. 2018, Wilkinson et al. 2018). Auklets hold high potential to be used as an indicator species, but may be sensitive to biologging because pronounced tagging effects have been observed in other puffins (e.g. F. cirrhata, Whidden et al. 2007).

The objectives for this study were to (1) quantify and distinguish effects of handling and tagging on the breeding success of rhinoceros auklets, and (2) test whether handling and tagging effects differ across breeding stages. We used an experimental approach to quantify and distinguish the effects of adult manipulation (none, handling, tagging) and breeding stage (early incubation, late incubation, early chick-rearing). We expected that less intensive procedures would cause less abandonment, and that abandonment would decrease as the breeding season progressed.

\section{MATERIALS AND METHODS}

\subsection{Study system}

We studied rhinoceros auklets breeding on Middleton Island, Alaska $\left(59.42^{\circ} \mathrm{N}, 146.32^{\circ} \mathrm{W}\right)$, sampling birds from 4 sub-colonies: Tower, Rhino Trail, Ship Trail, and Washwater (Fig. 1). During the breeding season, the auklets nest in burrows and have 2 distinct breeding stages: incubation and chick-rearing. Both parents incubate a single egg for 39-52 d (average: $46 \mathrm{~d}$ ), where they alternate daytime burrow attendance with their mate. During chick-rearing, adults are almost never in the burrow, as the chicks are semi-precocial and can thermoregulate within $2 \mathrm{~d}$ of hatching. Instead, adults spend the day resting or foraging and only return to the colony at night to incubate or feed their chick with a 'bill load' (Davoren \& Burger 1999).

To find active auklet burrows, we searched for signs of activity at the entrance (e.g. feathers, guano) during mid- to late May. We used a series of access holes to find the nest chamber. Once an egg was dis- 


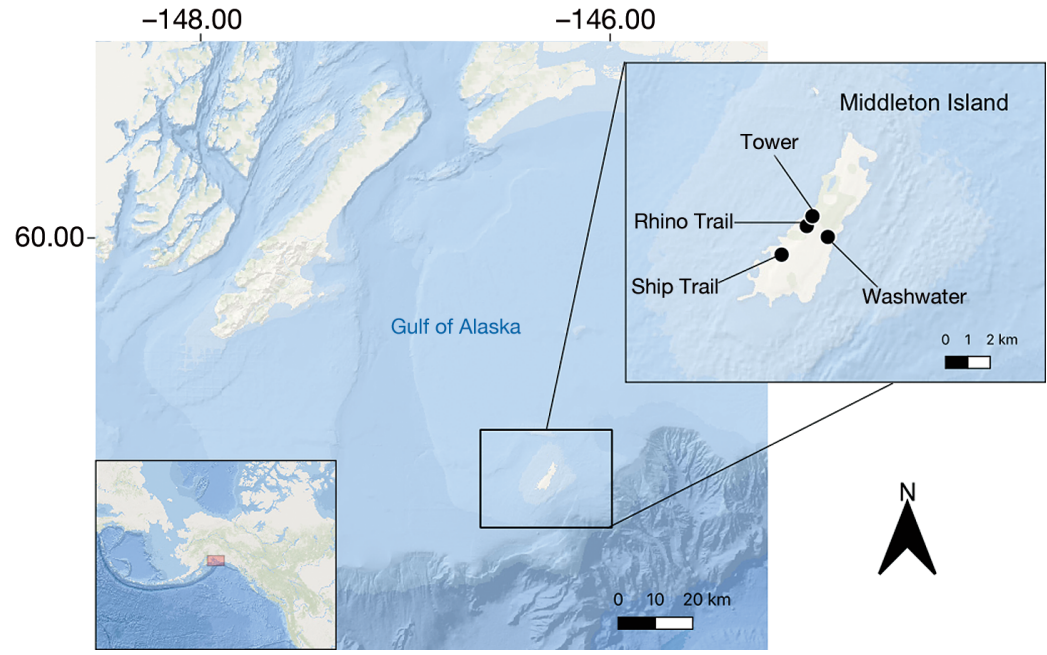

Fig. 1. Study area indicating rhinoceros auklet sub-colonies sampled. Coordinates are decimal degrees

covered, usually attended by a bird, we estimated egg development by measuring the angle or height of the egg when placed in a container of water (see Section 2.2). We then closed access holes and labeled the access hole nearest to the nest chamber with an orange rock so that the burrow could be monitored for the rest of the breeding season.

\subsection{Egg flotation}

To estimate egg development, we used the egg flotation method, which is known to be a reliable predictor of hatching date (Liebezeit et al. 2007). As the egg develops, the air pocket inside the egg grows larger, affecting its position inside a container of water (Fig. 2). Near the beginning of development, the egg is heavy, and sits almost horizontally at the bottom of the container. It then slowly tilts up until it reaches $90^{\circ}$. Subsequent development increases the buoyancy of the egg, causing it to float at a $90^{\circ}$ angle. At that point, the angle no longer changes but the egg becomes increasingly buoyant, so the height the egg is floating above the water must be measured (thus requiring 2 different measurements). By taking these measurements, we were able to estimate laying date and apply treatment groups appropriately (outlined in Section 2.3).

\subsection{Adult manipulations}

To test the effects of handling and tagging on rhinoceros auklets, we used 3 levels of manipulation intensity: LOW (no handling control), MODERATE (minimal handling), and HIGH (GPS deployment).

Low (no handling control): we monitored the burrow for hatching phenology by checking the contents of the nest chamber every $5 \mathrm{~d}$, starting May 31 and ending when the egg hatched. At each visit, we noted whether an adult was present in the nest chamber as well as the temperature of the egg (warm, cold). If the adult bird was present it was occasionally touched, but never captured or manipulated.

Moderate (minimal handling): this procedure mirrored the 'no handling control' treatment, except we also pulled an adult bird out of the burrow. Once removed from the burrow, we weighed, banded, bled the bird by clipping its toenail and collected a small blood sample with a capillary tube $(25-50 \mu \mathrm{l})$, and measured horn length, bill depth, culmen, and headbill. All captures took place during daytime.

HigH (GPS deployment): this procedure mirrored the 'minimal handling' treatment, with the addition of logger attachment and retrieval; procedures were split between the two captures to make the initial handling time similar to the MODERATE treatment (details in Section 2.4). All deployments took place during daytime; early chick-rearing recaptures took place at night (see Section 2.4).
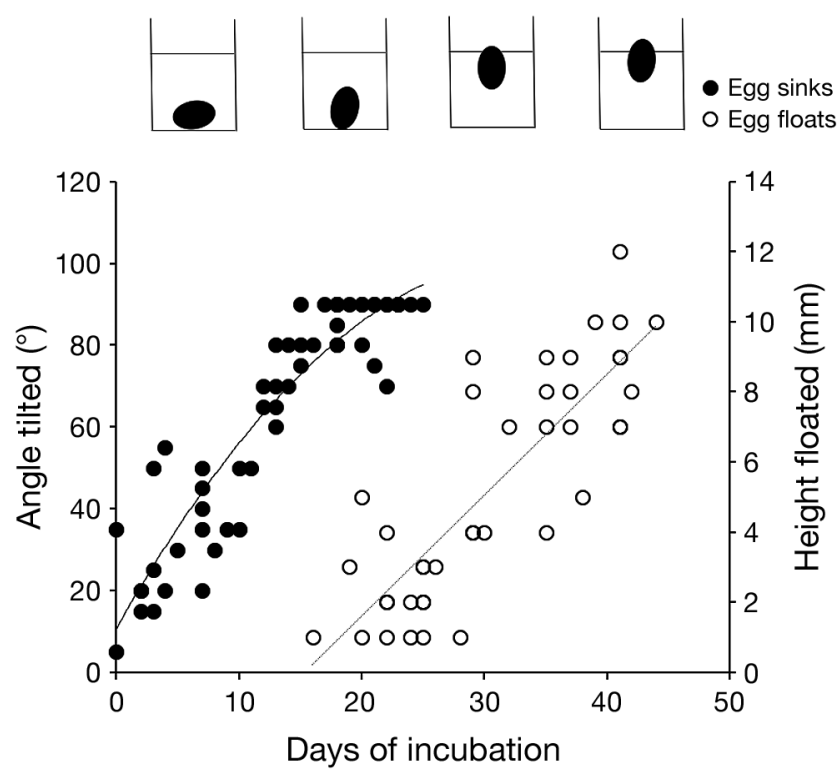

Fig. 2. Angles (for eggs that sank) and heights above water (for eggs that floated) in relation to the number of days incubated by rhinoceros auklets 
We assigned 151 burrows to the 3 groups using a random number generator. In total, 60 burrows were assigned for burrow monitoring (LOW), in accordance with existing long-term productivity monitoring protocols at the field site. The remaining burrows were then divided into the other 2 treatments (MODERATE and HIGH). To avoid spatial pseudoreplication, each manipulation intensity treatment included birds from $3 / 4$ of the sub-colonies. The application of treatments coincided with 3 breeding stages (early incubation: $\mathrm{n}=20$ MODERATE, $\mathrm{n}=0 \mathrm{HIGH}$; late incubation: $\mathrm{n}=15$ MODERATE, $\mathrm{n}=30 \mathrm{HIGH}$; early chick-rearing: $\mathrm{n}=11$ MODERATE, $\mathrm{n}=15 \mathrm{HIGH}$; Table 1); timing was determined by egg flotation (described previously; Fig. 2). We recorded the number of times each burrow was visited before the MODERATE or HIGH treatments, where we counted all visits (including date first accessed) before handling date (date handled was excluded). We measured handling duration for MODERATE and HIGH treatment groups as the time elapsed between capture from the burrow and release after manipulation (at GPS deployment for HIGH).

To maximize chances of finding an adult and a chick in the burrow during early chick-rearing, we checked burrows allocated to MODERATE and HIGH manipulation intensity treatments in early chick-rearing every 2-3 d preceding the anticipated hatch date, because the adult is only in the burrow during the day within the first $2-3 \mathrm{~d}$ of hatching. Some birds $(n=13)$ abandoned their nest before a manipulation was applied, and thus were excluded from this investigation.

\subsection{GPS deployment and retrieval}

We deployed GPS devices (Catlog Gen 2; $12.1 \pm$ $0.3 \mathrm{~g}$ ) on auklets (body mass: $527.9 \pm 6.3 \mathrm{~g}$ ) during late incubation and early chick-rearing. We deployed a total of 45 devices (incubation: $\mathrm{n}=30$; chick-rearing: $\mathrm{n}=15$ ). GPS devices were packaged in clear heat-shrink tubing to waterproof, making them $\sim 2.3 \%$ of the bird's body mass.

Table 1. Sample sizes for manipulation intensities and breeding stages of rhinoceros auklets on Middleton Island, Alaska. The Low intensity was a decreasing subset of 60 burrows designated as controls

\begin{tabular}{|lccc|}
\hline $\begin{array}{l}\text { Manipulation } \\
\text { intensity }\end{array}$ & $\begin{array}{c}\text { Early } \\
\text { incubation }\end{array}$ & $\begin{array}{c}\text { Late } \\
\text { incubation }\end{array}$ & $\begin{array}{c}\text { Early } \\
\text { chick-rearing }\end{array}$ \\
\hline LOW & 60 & 52 & 35 \\
MODERATE & 20 & 15 & 11 \\
HIGH & 0 & 22 & 15 \\
\hline
\end{tabular}

The handling procedure differed slightly than minimally handled birds, as manipulations were split between deployment and retrieval to minimize initial handling duration. Upon deployment, we weighed the bird, took a small blood sample by clipping the toenail, banded the bird, and attached a GPS device. We attached the device to the back feathers, $1-2 \mathrm{~cm}$ above the preen gland, using superglue, tesa marine adhesive tape, and cable ties.

Retrieval attempts began $4 \mathrm{~d}$ after deployment, and took place during the day for incubation and at night for chick-rearing (as adults do not attend to chicks during the day). During chick-rearing, we checked the burrow for the targeted bird 3 or 4 times per night, starting $1 \mathrm{~h}$ after sunset, until the logger was retrieved. Upon recapture, we removed the device and measured weight and morphometrics (horn length, bill depth, culmen, headbill). Average length of deployment was $4.4 \pm 0.3 \mathrm{~d}$.

\subsection{Breeding success and abandonment}

To evaluate handling effects on breeding success in auklets, we monitored burrows for nest abandonment (yes/no) after each treatment. Due to the nature of the experiment, the definitions for abandonment differed slightly between treatments, but followed a threshold of $15 \mathrm{~d}$ because we observed that most burrows were abandoned $7 \mathrm{~d}$ after manipulation (Fig. S1 in the Supplement at www.int-res. com/articles/suppl/m643p173_supp.pdf; mean: $9.2 \pm$ $1.1 \mathrm{~d}$, excluding 1 outlier that abandoned $31 \mathrm{~d}$ after manipulation).

The specific definitions are as follows: Low (no handling control): since no manipulation took place, abandonment was determined in the following way to ensure a fair comparison with manipulated treatments. All Low treatment burrows $(\mathrm{n}=60)$ were included in early incubation comparisons and considered abandoned if abandonment occurred within $15 \mathrm{~d}$ of first access (early May). In late incubation, only burrows active when regular burrow checks began (beginning of June) were included and considered abandoned if abandonment occurred within $15 \mathrm{~d}$ of the first burrow check. In early chick-rearing, we only included burrows in which a chick had hatched, and considered it abandoned if abandonment occurred within $15 \mathrm{~d}$ of hatching (mid to late June). MODERATE and HIGH treatments: abandonment was defined as desertion within $15 \mathrm{~d}$ of treatment application (i.e. an egg not incubated for $15 \mathrm{~d}$ [cold] or a dead chick). 


\subsection{Estimates of lay and hatch dates}

We estimated laying date for each burrow using 2 methods. If a chick successfully hatched, we estimated hatch and laying dates using the following equations:

$$
\begin{aligned}
\text { Hatch date }= & (\text { date first seen as chick }- \\
& \text { date last seen as egg }) / 2 \\
\text { Laying date }= & (\text { est. hatch date })-[46 \mathrm{~d} \\
& (\text { avg. incubation period })]
\end{aligned}
$$

If an egg did not hatch, we used egg float angle/height to estimate the number of days incubated (DI), because DI was a strong predictor of the angle tilted (Eq. 3: $\mathrm{R}^{2}=0.85, F_{1,52}=6.1, \mathrm{p}<0.05$ ) and height floated (Eq. $4: \mathrm{R}^{2}=0.70, F_{1,38}=87.2, \mathrm{p}<0.001$ ) among the sample of eggs for which hatching dates were eventually determined. The equations are as follows (see Table S1): for the egg angle (in ${ }^{\circ}$ ) in response to DI (for eggs that sank):

$$
\begin{aligned}
\text { Angle }= & \mathrm{DI}^{2} \times-0.08( \pm 0.03 \mathrm{SE})+ \\
& \mathrm{DI} \times 5.31( \pm 0.80 \mathrm{SE})+10.57
\end{aligned}
$$

For egg height (in $\mathrm{mm}$ ) in response to DI (for eggs that floated):

$$
\text { Height }=\mathrm{DI} \times 0.34( \pm 0.04 \mathrm{SE})-5.32
$$

Once the DI for the date that the egg was measured was determined, we could then back-calculate lay date:

$$
\begin{gathered}
\text { Estimated laying date = } \\
\text { (date of egg flotation test) - (est. DI) }
\end{gathered}
$$

\subsection{Statistical analyses}

All statistical analyses were performed in R v.3.5.1 (R Core Team 2019). All models were binomial generalised linear models (GLMs) using a chi-squared significance test, unless otherwise stated. When interactive effects were non-significant, we removed the interaction term and tested for main effects. We compared body mass at deployment to body mass at retrieval with a paired $t$-test.

\subsubsection{Effects of laying date and date first accessed on breeding success}

We modeled hatching success (0/1) and fledging success $(0 / 1)$, in response to laying date and date first accessed within the control group of burrows $(\mathrm{n}=$ $60)$. We did not include the number of visits as a pre- dictor because we checked the burrow every $5 \mathrm{~d}$ for this group, which standardized visits to the burrow.

\subsubsection{Effects of breeding stage on abandonment}

We tested for effects of breeding stage on abandonment among LOW and MODERATE groups, excluding the HIGH group because no birds received HIGH treatment in early incubation. We modeled abandonment $(0 / 1)$ in response to breeding stage, manipulation intensity, and a 2-way interaction.

\subsubsection{Effects of handling and tagging on abandonment}

We extracted 75 birds from the burrow for either MODERATE or HIGH manipulation treatments during late incubation and early chick-rearing. We tested for effects of manipulation intensity (MODERATE/HIGH), breeding stage, handling duration, and an interactive effect between manipulation intensity and breeding stage on abandonment. We did not include number of visits to the burrow prior to handling, because this correlated with breeding stage but not manipulation treatment (Fig. S2). We modeled handling duration in response to breeding stage and manipulation intensity (linear model; Type II ANOVA). We compared abandonment of MODERATE and HIGH twice: (1) using abandonment among HIGH burrows post-deployment, then (2) including total HIGH abandonment (including both post-deployment and postretrieval abandonment).

\section{RESULTS}

Abandonment increased with manipulation intensity and decreased as the breeding season progressed (Fig. 3).

\subsection{Effects of laying date and date first accessed on breeding success}

Among control (LOW burrows, we found no significant effect of laying date $(0.01 \pm 0.05$, deviance $=$ $0.11, \mathrm{df}=1, \mathrm{p}=0.74)$ or date first accessed $(-0.06$ \pm 0.06 , deviance $=0.83$, df $=1, \mathrm{p}=0.36$ ) on hatching success. Only 1 out of 36 chicks that hatched died before fledging, thus we observed no significant effect of laying date $(0.03 \pm 0.05$, deviance $=$ 


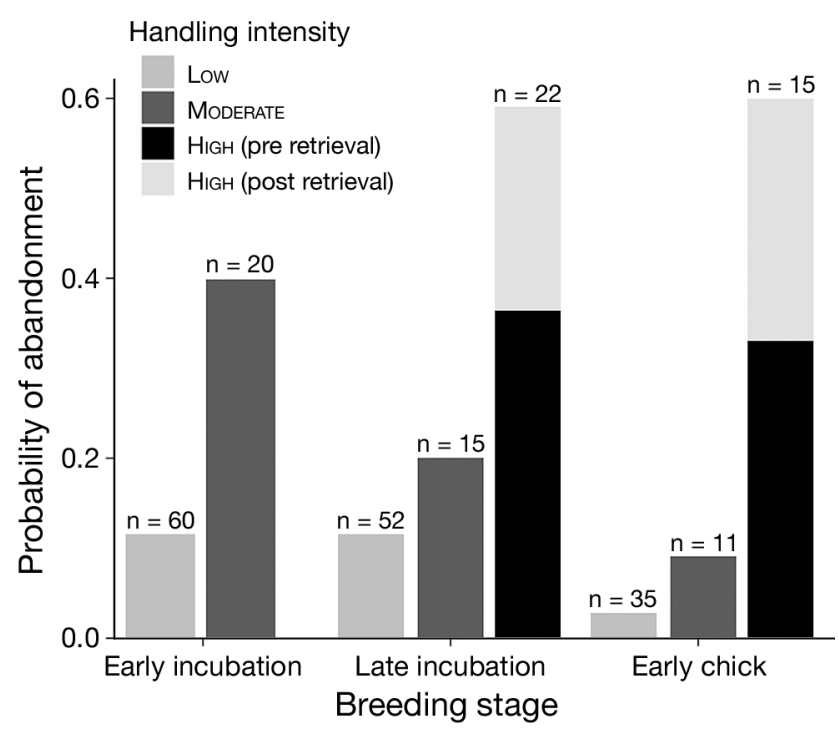

Fig. 3. Probability of rhinoceros auklet nest abandonment across breeding stages and manipulation intensities ( $\mathrm{n}=$ 151)

0.38, $\mathrm{df}=1, \mathrm{p}=0.54)$ or date first accessed $(-0.06$ \pm 0.06 , deviance $=0.84, \mathrm{df}=1, \mathrm{p}=0.36$ ) on fledging success.

\subsection{Effects of breeding stage on abandonment}

Among LOW and MODERATE treated burrows, we did not find a significant interaction between manipulation intensity and breeding stage (deviance $=1.0, \mathrm{df}=$ $2, \mathrm{p}=0.61)$. We removed the interaction term and found that MODERATE treated burrows had significantly higher abandonment than control burrows $(1.2 \pm 0.4$, deviance $=7.4, \mathrm{df}=1, \mathrm{p}<0.01)$, and breeding stage significantly influenced abandonment $($ deviance $=6.0, \mathrm{df}=2, \mathrm{p}<0.05$ ). Differences in abandonment across breeding stages were largely driven by early incubation-early chick rearing $(1.7 \pm 0.8, z=2.1, p=0.09)$, rather than early incubation-late incubation $(0.4 \pm 0.5, z=0.8, p=$
$0.70)$ or late incubation-early chick rearing (1.3 \pm $0.8, z=1.6, \mathrm{p}=0.26)$.

\subsection{Effects of handling and tagging on abandonment}

We obtained a complete set of measurements for 57 of 75 individuals handled during late incubation or early chick-rearing. Despite efforts to standardize manipulations throughout the experiment, handling duration was $4.5 \pm 0.6$ min longer for the HIGH treatment $\left(F_{1,60}=48.8, \mathrm{p}<0.001\right)$ and $2.0 \pm 0.6$ min shorter during early chick-rearing $\left(F_{1,60}=10.3\right.$, p $<0.01$; Fig. S3).

Breeding stage and manipulation intensity did not interactively affect post-deployment abandonment (deviance $=0.1, \mathrm{df}=1, \mathrm{p}=0.76$ ) or total abandonment (deviance $=0.2, \mathrm{df}=1, \mathrm{p}=0.63$ ), so we removed the interaction term from both models and tested for main effects only. Manipulation intensity was the only significant predictor of both post-deployment and total abandonment, where birds that were handled but not tagged were less likely to abandon (Table 2). Breeding stage, handling duration, and laying date did not significantly influence abandonment (Table 2).

\subsection{Additional tagging details}

For the HIGH treatment, we retrieved a total of 28 of 45 devices (incubation: $\mathrm{n}=18 / 30$; chick-rearing: $\mathrm{n}=$ 10/15), meaning that 17 birds abandoned postdeployment (incubation: $\mathrm{n}=12$; chick-rearing: $\mathrm{n}=5$ ). However, we also noted that nest abandonment increased upon retrieval, as handling had to occur twice. As a result, a total of 27 birds abandoned from the experiment (incubation: $\mathrm{n}=18$; chick-rearing: $\mathrm{n}=$ 9). Table 3 shows abandonment rates after deployment and retrievals. On average, birds lost $17.3 \mathrm{~g}$ during the deployment $\left(t_{19}=3.5, \mathrm{p}<0.01\right)$.

Table 2. Parameter estimates for models of post-deployment and total abandonment of rhinoceros auklets among MODERATE and HIGH manipulation intensity groups during late incubation and early chick-rearing

\begin{tabular}{|c|c|c|c|c|c|c|c|c|}
\hline \multirow[b]{2}{*}{ Predictor } & \multicolumn{4}{|c|}{ — Post-deployment abandonment — } & \multicolumn{3}{|c|}{ Total abandonment } & \multirow{2}{*}{$\mathrm{p}$-value } \\
\hline & Estimate $\pm \mathrm{SE}$ & Deviance & df & p-value & Estimate $\pm \mathrm{SE}$ & Deviance & df & \\
\hline Intercept & $5.0 \pm 7.5$ & - & - & - & $13.5 \pm 8.5$ & - & - & - \\
\hline Breeding stage: late incubation & $0.5 \pm 0.7$ & 0.09 & 1 & 0.77 & $0.4 \pm 0.7$ & 0.009 & 1 & 0.92 \\
\hline Manipulation intensity: MODERATE & $-2.2 \pm 1.0$ & 5.0 & 1 & 0.03 & $-3.7 \pm 1.2$ & 14.5 & 1 & 0.0001 \\
\hline Handling duration & $-0.2 \pm 0.1$ & 1.7 & 1 & 0.19 & $-0.3 \pm 0.2$ & 3.5 & 1 & 0.06 \\
\hline Laying date & $-0.03 \pm 0.06$ & 0.2 & 1 & 0.64 & $-0.08 \pm 0.07$ & 1.6 & 1 & 0.21 \\
\hline
\end{tabular}


Table 3. Nest abandonment (\%) of rhinoceros auklets upon GPS retrieval

\begin{tabular}{|lcc|}
\hline & $\begin{array}{c}\text { Late incubation } \\
\mathrm{n}=22\end{array}$ & $\begin{array}{c}\text { Early chick-rearing } \\
\mathrm{n}=15\end{array}$ \\
\hline Abandonment & & \\
After deployment & 36.4 & 33.3 \\
After retrieval & 22.7 & 26.7 \\
Total & 59.0 & 60.0 \\
Retrieval success & 63.6 & 67.7 \\
\hline
\end{tabular}

\section{DISCUSSION}

We applied an experimental approach to distinguish the effects of handling and tagging on breeding success of rhinoceros auklets relative to unmanipulated controls. Consistent with predictions, nest abandonment increased with manipulation intensity but decreased with breeding stage. Natural abandonment declined as the breeding season progressed, possibly due to selective disappearance of low-quality parents (van de Pol \& Verhulst 2006) and/or increased parental investment (Winkler 1987). Handling alone increased abandonment relative to controls, but abandonment declined in both groups as the breeding season progressed. Tagging during late incubation and early chick-rearing had a greater effect on abandonment than handling alone. Thus, both handling and tags that weighed $<3 \%$ of body mass caused abandonment. Auklets were least likely to abandon in response to handling during early chick-rearing, indicating that manipulations should be delayed until chickrearing when possible.

This experimental approach produced several data-driven recommendations for future biologging studies on rhinoceros auklets, many of which concur with existing recommendations (see Elliott 2016, Bodey et al. 2018). First, researchers should avoid handling and tagging early in the breeding season, if unnecessary to address the research question. Second, if manipulations must happen during incubation, we recommend late-incubation procedures and use of egg flotation to estimate phenology and reduce investigator disturbance at the nest site. Though the regression equations produced via egg flotation are specific to rhinoceros auklets, they may be applicable to other alcid species. Further, this technique could be broadly applied to other seabird species at coarser scales; for example, a binary response (sink vs. float) alone can be highly informative about embryo development (sink = less devel- oped; float $=$ more developed). Third, we recommend avoiding multiple handling events, for example by using GPS units that download remotely but detach after several days, obviating the need for recapture. Both the initial tagging and subsequent handling during GPS retrieval caused substantial abandonment. Considering that devices requiring only one handling event can still cause tagging effects, a device that does not detach after several days could therefore cause an equal or greater decrease in fitness. Fourth, we recommend using the smallest and lightest tag available to meet research needs. Devices $<3 \%$ of body weight negatively impacted breeding success of rhinoceros auklets in this study, and devices may need to be $<1 \%$ for negative effects to not be detected (Bodey et al. 2018). For example, we observed a decline in abandonment as the breeding season progressed despite using the same manipulation procedure; increased commitment to the breeding attempt, not decreased physiological effects of handling, is the most likely driver of this pattern. Smaller tags are less likely to cause tag effects and more likely to produce data that reflect natural behavior.

We examined the effects of manipulation on a single, sensitive species. The rhinoceros auklet is an auk species and a short-winged, wing-propelled diver; a review of tag effects in auks showed widespread impacts of devices $3 \%$ of body size, possibly because the high wing loading of this family means that they are particularly susceptible to increases in loading (Elliott et al. 2010, Vandenabeele et al. 2012). Responses to devices found in this study might be shared by other auk species and other species of different seabird families known to exhibit greater tagging effects (e.g. shearwaters; Söhle et al. 2000, Villard et al. 2011). However, a metanalysis found little evidence for phylogenetic heritability of tag effects (Bodey et al. 2018), suggesting that tag effects are likely linked to species-specific morphology, behavior, and ecology. We used individuals that had never been captured in the burrow, but it is possible that continued researcher presence could habituate birds to human disturbance (Burger \& Gochfeld 1999) or select for tolerant individuals. Although we found a decrease in abandonment as the breeding season progressed, we did not manipulate birds after early chick-rearing. It is possible that abandonment continues to decline throughout chick-rearing, but we did not include this breeding phase. An important factor to note is that, despite best efforts to standardize manipulations, the tagged birds experienced longer handling durations and burrows allocated 
to later treatments experienced more researcher visits. Thus, we might be underestimating the effects of handling duration on abandonment and underestimating the decline in abandonment due to breeding stage. Finally, it is important to acknowledge that the small sample size per treatment group in this study may explain statistically non-significant effects (e.g. post hoc tests, handling duration). We emphasize that, despite these limitations, the experimental approach could be applied to improve manipulation and biologging practices in almost any seabird system.

This study raises a difficult question: do the conservation and knowledge benefits of a biologging study exceed the fitness costs to the study individuals? For marine health indicators that are sensitive to researcher disturbance, such as the rhinoceros auklet, what is good for understanding the population, species, seabird community, and regional ocean health is clearly costly to individual breeding success in the study year. However, long-term diet monitoring data from this population of rhinoceros auklet has produced valuable knowledge on greater ecosystem dynamics (e.g. Sydeman et al. 2017, Cunningham et al. 2018, Thompson et al. 2019); individual movement data provide necessary context to interpret these diet data. We suggest that when the conservation and knowledge benefits of a biologging study exceed the fitness costs to the study individuals, failure rates are acceptable, while acknowledging that the currencies involved may not be immediately comparable or easy to measure. In the context of this particular study, we believe that these findings will decrease future research-induced failure rates (reducing negative impacts on individuals and population) and increase data returns in future studies (increasing positive impacts on marine conservation and management).

In conclusion, we advocate a data-driven approach to reduce impacts of biologging on a given study species. We recommend incorporating experimental designs into biologging studies, such as the one used here, that allow for quantification of investigator effects - customized to the study system - that will improve future field methodology.

Acknowledgements. We thank Alyssa Piauwasdy, Luis Ramos, and Hannes Schraft for their assistance in the field. This work was supported by NSERC (A.S., S.W., K.H.E.), a Canada Research Chair in Arctic Ecology (K.H.E.), and the Institute for Seabird Research and Conservation (S.A.H.). Three anonymous reviewers provided feedback that greatly improved the quality of the manuscript.

\section{LITERATURE CITED}

Ackerman JT, Adams J, Takekawa JY, Carter HR and others (2004) Effects of radiotransmitters on the reproductive performance of Cassin's auklets. Wildl Soc Bull 32: 1229-1241

*Backmer AL, Ackerman JT, Nevitt GA (2004) Effects of investigator disturbance on hatching success and nestsite fidelity in a long-lived seabird, Leach's storm-petrel. Biol Conserv 116:141-148

Bodey TW, Jessopp MJ, Votier SC, Gerritsen HD and others (2014) Seabird movement reveals the ecological footprint of fishing vessels. Curr Biol 24:R514-R515

Bodey TW, Cleasby IR, Bell F, Parr N, Schultz A, Votier SC, Bearhop S (2018) A phylogenetically controlled metaanalysis of biologging device effects on birds: deleterious effects and a call for more standardized reporting of study data. Methods Ecol Evol 9:946-955

Brisson-Curadeau E, Patterson A, Whelan S, Lazarus T, Elliott KH (2017) Tracking Cairns: biologging improves the use of seabirds as sentinels of the sea. Front Mar Sci $4: 357$

*Burger J, Gochfeld M (1999) Role of human disturbance in response behavior of Laysan albatrosses (Diomedea immutabilis). Bird Behav 13:23-30

*Burger AE, Shaffer SA (2008) Perspectives in ornithology: application of tracking and data-logging technology in research and conservation of seabirds. Auk 125: 253-264

* Burger AE, Wilson RP, Garnier D, Wilson MPT (1993) Diving depths, diet, and underwater foraging of rhinoceros auklets in British Columbia. Can J Zool 71:2528-2540

* Carey MJ (2009) The effects of investigator disturbance on procellariiform seabirds: a review. N Z J Zool 36:367-377

* Carle RD, Beck JN, Calleri DM, Hester MM (2015) Temporal and sex-specific variability in rhinoceros auklet diet in the central California Current System. J Mar Syst 146: 99-108

Croll DA, John KJ, Michael EG, Boveng PL, Bengtson JL (1996) Foraging behavior and reproductive success in chinstrap penguins: the effects of transmitter attachment. J Field Ornithol 67:1-9

Cunningham JT, Elliott KH, Cottenie K, Hatch SA, Jacobs SR (2018) Individual foraging location, but not dietary, specialization: implications for rhinoceros auklets as samplers of forage fish. Mar Ecol Prog Ser 605:225-240

*Davoren GK (2000) Variability in foraging in response to changing prey distributions in rhinoceros auklets. Mar Ecol Prog Ser 198:283-291

* Davoren GK, Burger AE (1999) Differences in prey selection and behaviour during self-feeding and chick provisioning in rhinoceros auklets. Anim Behav 58:853-863

* Elliott KH (2016) Measurement of flying and diving metabolic rate in wild animals: review and recommendations. Comp Biochem Physiol A Mol Integr Physiol 202:63-77

Elliott KH, Shoji A, Campbell KL, Gaston AJ (2010) Oxygen stores and foraging behavior of two sympatric, planktivorous alcids. Aquat Biol 8:221-235

Fraser G, Jones IL, Williams JC, Hunter FM, Scharf L, Byrd GV (1999) Breeding biology of crested auklets at Buldir and Kasatochi islands, Alaska. Auk 116:690-701

Gaston AJ, Elliott KH, Ropert-Coudert Y, Kato A, Macdonald CA, Mallory ML, Gilchrist HG (2013) Modeling foraging range for breeding colonies of thick-billed murres Uria lomvia in the eastern Canadian Arctic and potential 
overlap with industrial development. Biol Conserv 168: 134-143

Götmark F (1992) The effects of investigator disturbance on nesting birds. In: Power DM, (ed) Current ornithology, Vol 9. Springer, Boston, MA, p 63-104

Hatch SA (2013) Kittiwake diets and chick production signal a 2008 regime shift in the Northeast Pacific. Mar Ecol Prog Ser 477:271-284

Hatch SA, Meyers PM, Mulcahy DM, Douglas DC (2000) Performance of implantable satellite transmitters in diving seabirds. Waterbirds 23:84-94

Kato A, Watanuki Y, Naito Y (2003) Foraging behaviour of chick-rearing rhinoceros auklets Cerorhinca monocerata at Teuri Island, Japan, determined by acceleration-depth recording micro data loggers. J Avian Biol 34:282-287

Lescroël A, Mathevet R, Péron C, Authier M, Provost P, Takahashi A, Grémillet D (2016) Seeing the ocean through the eyes of seabirds: A new path for marine conservation? Mar Policy 68:212-220

Liebezeit JR, Smith PA, Lanctot RB, Schekkerman H and others (2007) Assessing the development of shorebird eggs using the flotation method: species-specific and generalized regression models. Condor 109:32-47

Piatt JF, Roberts BD, Wayne WL, John LW, Hatch SA (1990) Effects of human disturbance on breeding least and crested auklets at St. Lawrence Island, Alaska. Auk 107: 342-350

Piatt JF, Sydeman WJ, Wiese F (2007) Introduction: seabirds as indicators of marine ecosystems. Mar Ecol Prog Ser 352:199-204

Portugal SJ, White CR (2018) Miniaturization of biologgers is not alleviating the $5 \%$ rule. Methods Ecol Evol 9: 1662-1666

R Core Team (2019) R: a language and environment for statistical computing. R Foundation for Statistical Computing, Vienna. www.R-project.org/

Rodway MS, Montevecchi WA, Chardine JW (1996) Effects of investigator disturbance on breeding success of Atlantic puffins Fratercula arctica. Biol Conserv 76:311-319

Sandvik H, Barrett RT (2001) Effect of investigator disturbance on the breeding success of the black-legged kittiwake. J Field Ornithol 72:30-42

Söhle IS, Moller H, Fletcher D, Robertson CJR (2000) Telemetry reduces colony attendance by sooty shearwaters (Puffinus griseus). N Z J Zool 27:357-365

Sydeman WJ, Hester MM, Thayer JA, Gress F, Martin P, Buffa J (2001) Climate change, reproductive perfor-

Editorial responsibility: Thierry Boulinier,

Montpellier, France mance and diet composition of marine birds in the Southern California Current System, 1969-1997. Prog Oceanogr 49:309-329

* Sydeman WJ, Piatt JF, Thompson SA, García Reyes M and others (2017) Puffins reveal contrasting relationships between forage fish and ocean climate in the North Pacific. Fish Oceanogr 26:379-395

Thaxter CB, Ross-Smith VH, Clark JA, Clark NA and others (2016) Contrasting effects of GPS device and harness attachment on adult survival of lesser black backed gulls Larus fuscus and great skuas Stercorarius skua. Ibis 158: 279-290

* Thompson SA, García Reyes M, Sydeman WJ, Arimitsu ML, Hatch SA, Piatt JF (2019) Effects of ocean climate on the length and condition of forage fish in the Gulf of Alaska. Fish Oceanogr 28:658-671

* van de Pol M, Verhulst S (2006) Age-dependent traits: a new statistical model to separate within- and between-individual effects. Am Nat 167:766-773

*Vandenabeele SP, Shepard EL, Grogan A, Wilson RP (2012) When three per cent may not be three per cent; deviceequipped seabirds experience variable flight constraints. Mar Biol 159:1-14

Villard P, Bonenfant C, Bretagnolle V (2011) Effects of satellite transmitters fitted to breeding Cory's shearwaters. J Wildl Manag 75:709-714

*Wakefield ED, Phillips RA, Matthiopoulos J (2009) Quantifying habitat use and preferences of pelagic seabirds using individual movement data: a review. Mar Ecol Prog Ser 391:165-182

WWatanuki Y, Ito M, Deguchi T, Minobe S (2009) Climateforced seasonal mismatch between the hatching of rhinoceros auklets and the availability of anchovy. Mar Ecol Prog Ser 393:259-271

*Whidden SE, Williams CT, Breton AR, Buck CL (2007) Effects of transmitters on the reproductive success of tufted puffins. J Field Ornithol 78:206-212

*Wilkinson BP, Jahncke J, Warzybok P, Bradley RW, Shaffer SA (2018) Variable utilization of shelf break-associated habitats by chick-brooding rhinoceros auklets in the California Current System. Mar Ecol Prog Ser 590:211-226

Wilson RP, Grémillet D, Syder J, Kierspel MAM and others (2002) Remote-sensing systems and seabirds: their use, abuse and potential for measuring marine environmental variables. Mar Ecol Prog Ser 228:241-261

*Winkler DW (1987) A general model for parental care. Am Nat 130:526-543

Submitted: October 17, 2019; Accepted: April 20, 2020

Proofs received from author(s): May 26, 2020 